\title{
Prevalence of thyroid dysfunction and impact on maternal and fetal outcome in Central Indian pregnant women
}

\author{
Joysee Pokhanna, Urvi Gupta*, Madhuri Alwani, Shruti Pathak Tiwari
}

Department of Obstetrics and Gynecology, Sri Aurobindo Medical, College and PG Institute, Indore, Madhya Pradesh India

Received: 25 August 2017

Accepted: 01 September 2017

*Correspondence:

Dr. Urvi Gupta,

E-mail: dr.urvigupta94@gmail.com

Copyright: () the author(s), publisher and licensee Medip Academy. This is an open-access article distributed under the terms of the Creative Commons Attribution Non-Commercial License, which permits unrestricted non-commercial use, distribution, and reproduction in any medium, provided the original work is properly cited.

\section{ABSTRACT}

Introduction: Thyroid dysfunctions have become common endocrine problems in pregnant women. It is now well established that not only overt, but subclinical thyroid dysfunction also has adverse effects on maternal and fetal outcome. There are very few data from India about the prevalence of thyroid dysfunction in pregnancy. In this study, we determined the prevalence of thyroid dysfunction in pregnancy and its impact on obstetrical outcome in Central Indian Indore Pregnant Women.

Methods: Total 300 pregnant women between the 13 and 26 weeks of gestation were recruited for this study who is residing in Indore. In all patients routine obstetrical investigations, TSH tests were done. Anti-TPO antibody tests and Free T4 were done in patients with deranged TSH. The obstetrical and perinatal outcomes were recorded. Almost all the patients were followed up to delivery.

Results: The prevalence of hypothyroidism and hyperthyroidism was 13 and 4\%, respectively. Adverse maternal effects in overt hypothyroidism included preeclampsia $(22.2$ versus $11.6 \%)$ and placental abruption $(22.2$ versus $2.0 \%)$. Subclinical hypothyroidism was associated with preeclampsia (30.0 versus $11.6 \%)$ as compared to the euthyroid patients. Adverse fetal outcomes in overt hypothyroidism included spontaneous abortion (22.2 versus $6.6 \%$ ), preterm birth (44.4 versus $30.0 \%$ ), low birth weight (66.6 versus 30.0\%), intrauterine growth retardation (33.3 versus $10.0 \%)$, and fetal death $(22.2$ versus $0 \%)$ as compared to the euthyroid women. Adverse fetal outcomes in subclinical hypothyroidism included spontaneous abortion (2.0 versus $6.6 \%)$, preterm delivery $(5.2$ versus $30.0 \%)$, low birth weight $(11.2$ versus $30.0 \%)$, and intrauterine growth retardation (4.4 versus $10 \%)$ as compared to the euthyroid women.

Conclusions: The prevalence of thyroid disorders was high in our study with associated adverse maternal and fetal outcomes. Routine screening of thyroid dysfunction is recommended to prevent adverse fetal and maternal outcome.

Keywords: Central-Indian, Maternal and fetal outcome, Pregnant women, Thyroid dysfunction

\section{INTRODUCTION}

Thyroid hormones have profound variation during the life span and are associated with severe adverse health impacts. ${ }^{1,2}$ Pregnancy, as an important reproductive event, has a profound but reversible effect on the thyroid gland and its functions. Pregnancy is actually a state of excessive thyroid stimulation leading to an increase in thyroid size by $10 \%$ in iodide sufficient areas and 20 $40 \%$ in iodide deficient regions. ${ }^{3}$ Moreover following the physiological and hormonal changes caused by pregnancy and human chorionic gonadotropin (HCG) the production of thyroxin (T4) and triiodothyronine (T3) increase up to $50 \%$ leading to $50 \%$ increase in a woman's 
daily iodide need, while Thyroid-stimulating hormone (TSH) levels are decreased, especially in first trimester. ${ }^{4}$

In an iodide sufficient area, these thyroid adaptations during pregnancy are well tolerated, as stored inner thyroid iodide is enough; however, in iodide deficient areas, these physiological adaptations lead to significant changes during pregnancy. ${ }^{5}$

Furthermore, in women who suffered from thyroid dysfunction prior to pregnancy, the hormonal changes mentioned are magnified, leading to possibly adverse pregnancy outcomes if not been treated appropriately. Moreover, the mode of delivery may additionally have adverse impact on fetal- pituitary- thyroid axis. ${ }^{6}$ The prevalence of thyroid dysfunction in pregnant women is relatively high so that overt thyroid dysfunction occurs in $2-3 \%$ of pregnancies, and subclinical dysfunction in $10 \%$ of pregnancies and thyroid autoimmunity is even more prevalent. $^{7,8}$ There is paucity of data on prevalence of thyroid disorders in Indian pregnant women; few reports show a prevalence of $4.8 \%$ to $11 \%$ amongst Indian pregnant population. ${ }^{9,10}$ In view of adverse maternal and fetal outcome in pregnant women with thyroid disorder and obvious benefits of early diagnosis and treatment, some expert panels all around the world have suggested routine thyroid function screening of all pregnant women. However, there are limited data on the prevalence of newly diagnosed thyroid disease during pregnancy from India. Therefore, this study was designed to evaluate the prevalence of thyroid dysfunction and impact on maternal and fetal outcome in Central-Indian, Indore pregnant women.

\section{METHODS}

This observational study was done in the Department of Obstetrics and Gynaecology at Sri Aurobindo Medical College and PG Institute, Indore. Prior permission form ethical committee of the hospital was taken. An informed consent was taken from all the study subjects. All patients were subjected to the usual history taking, clinical examination and ante-natal profile of investigations.

A total of 300 pregnant women from Indore Antenatal Clinics from March 2016 to March 2017 between 13 and 26 weeks of gestation were included in the study. All healthy pregnant women with no other medical disorder, with singleton pregnancy were included in the study. Patients with multifetal gestation, known thyroid and metabolic disorders like diabetes, hypertension, and a history of pregnancy loss were excluded from the study.

In addition to these tests, serum T3, T4, TSH and antiTPO antibody were done samples were collected at the same time as other investigations. The reference ranges of the test values used in this study were as per the 2011 Guidelines of American Thyroid Association for the Diagnosis (ATA) and Management of Thyroid Disease (MTD) during pregnancy. ${ }^{3}$ As per Regulation 14.2 of
ATA Guidelines, if trimester-specific ranges for TSH are not available in the laboratory, the following normal reference ranges are recommended: $1^{\text {st }}$ trimester -0.1 to $2.5 \mathrm{~m} \mathrm{IU} / \mathrm{L}, 2^{\text {nd }}$ trimester -0.2 to $3.0 \mathrm{~m} \mathrm{IU} / \mathrm{L}$ and $3^{\text {rd }}$ trimester -0.3 to $3.0 \mathrm{~m} \mathrm{IU/L}$. In pregnancy, serum total T4 measurement is recommended over direct immunoassay of free T4. Because of alterations in serum proteins in pregnancy free T4 assay may yield lower values based on reference ranges established with normal nonpregnant sera. ${ }^{11}$ Also method-specific and trimester specific reference ranges for direct immunoassays of free T4 have not been generally established. By contrast, total T4 increase during the $1^{\text {st }}$ trimester and the reference range throughout pregnancy is 1.5 -fold that of the nonpregnant range. ${ }^{12}$

\section{Statistical analyses}

All statistical analyses were performed using the Statistical Package of Social Sciences and Problem Solutions (SPSS-20). Bilateral Fischer's exact test was used to compare two different rates if the number of measures in any one group was $<5$. Continuous variables were presented as mean $\pm \mathrm{SD}$ and analyzed using unpaired, two-tailed student's t test. Analysis was done of the data obtained.

\section{RESULTS}

All the patients were divided according to thyroid function. Out of 300 patients, 51 (17\%) had deranged thyroid function, making the prevalence of thyroid dysfunction $17 \%$. Prevalence of hypothyroidism was $13 \%$, out of which in $3 \%$ had overt hypothyroidism and $10 \%$ had subclinical hypothyroidism. The prevalence of hyperthyroidism was $4 \%$, out of which $1.6 \%$ had overt hyperthyroidism and $2.4 \%$ had subclinical hyperthyroidism in the present study. Anti-TPO antibody was done in patients with deranged TSH levels. AntiTPO antibody was found positive in $40 \%$ of hypothyroid patients. No anti-TPO antibody was found in hyperthyroid patients.

The maternal age was high in the overt hypothyroid and overt hyperthyroid. In the present study, the mean BMI was $23.16 \pm 2.4$ for euthyroid patients, $22.17 \pm 1.8$ for subclinical hypothyroid, $23.67 \pm 1.2$ for overt hypothyroid, $22.52 \pm 0.9$ for subclinical hyperthyroid, and 21.8 \pm 1.20 for overt hyperthyroid (Table 1). The obese women had higher TSH concentration and were prone to hypothyroidism than normal weight women. No significant statistical difference was seen with respect to socioeconomic status and parity in different groups. Thyroid dysfunction is associated with adverse maternal and fetal outcomes in pregnancy. The data on hypothyroidism were more conclusive than in hyperthyroidism as the sample size in the hyperthyroidism group was small and the disease is comparatively infrequent. 
Table 2 shows the maternal complications in different groups were adverse maternal effects in overt hypothyroidism included preeclampsia (22.2 versus $11.6 \%)$ and placental abruption (22.2 versus $2.00 \%, \mathrm{P}=$ $0.008)$. No significant increase in anemia (11.1 versus $12.04 \%$ ), gestational diabetes mellitus (GDM) (11.1 versus $1.20 \%$ ), and postpartum hemorrhage (PPH) (11.1 versus $10.04 \%$ ) was seen in the overt hypothyroid group. Subclinical hypothyroidism was significantly associated with preeclampsia (30.0 versus $11.6 \%, \mathrm{P}=0.09)$ as compared to the euthyroid patients. No significant increase in anemia (13.3V/S $12.04 \%)$, placental abruption (3.3 versus $2.0 \%, \mathrm{P}=0.09)$, GDM (3.3 versus $1.20 \%)$, and PPH (6.6 versus $10.04 \%$ ) was seen in the subclinical hypothyroid patients. There were no maternal deaths in any of the groups.

No complications of myxoedema coma and thyroid storm were seen in our study.

Table 1: Obstetrical variable in the antenatal period.

\begin{tabular}{|lll|}
\hline Types & Age Mean \pm SD & BMI Mean \pm SD \\
\hline Euthyroid $(\mathrm{N}=249)$ & $26.46 \pm 2.83$ & $23.16 \pm 2.4$ \\
\hline Subclinical hypothyroidism $(\mathrm{N}=30)$ & $25.41 \pm 3.61$ & $22.17 \pm 1.8$ \\
\hline Overt hypothyroidism $(\mathrm{N}=9)$ & $27.23 \pm 4.33^{*}$ & $23.67 \pm 1.2^{*}$ \\
\hline Subclinical hyperthyroidism $(\mathrm{N}=7)$ & $25.21 \pm 1.42$ & $22.52 \pm 0.9$ \\
\hline Overt hyperthyroidism $(\mathrm{N}=5)$ & $29 . .59 \pm 1.70^{*}$ & $21.8 \pm 1.20^{*}$ \\
\hline
\end{tabular}

Table 2: Maternal complications in different groups.

\begin{tabular}{|c|c|c|c|c|c|}
\hline & $\begin{array}{l}\text { Euthyroid } \\
\mathbf{N}= \\
249 \mathbf{N}(\%)\end{array}$ & $\begin{array}{l}\text { Subclinical } \\
\text { hypothyroidism } \\
\text { N=30 N (\%) }\end{array}$ & $\begin{array}{l}\text { Overt } \\
\text { hypothyroidism } \\
\mathrm{N}=9 \mathrm{~N}(\%)\end{array}$ & $\begin{array}{l}\text { Subclinical } \\
\text { hyperthyroidism } \\
\mathbf{N}=7 \mathbf{N}(\%)\end{array}$ & $\begin{array}{l}\text { Overt } \\
\text { hyperthyroidism } \\
\mathrm{N}=5 \mathrm{~N}(\%)\end{array}$ \\
\hline \multicolumn{6}{|l|}{ Maternal Complications } \\
\hline Anemia & $30(12.04)$ & $4(13.3)$ & $1(11.1)$ & $1(14.2)$ & $1(20)$ \\
\hline Preeclampsia & $29(11.6)$ & $9(30.0)^{*}$ & $2(22.2)$ & 0 & 0 \\
\hline Abruption & $5(2.00)$ & $1(3.3)$ & $2(22.2)^{*}$ & 0 & 0 \\
\hline GDM & $3(1.20)$ & $1(3.3)$ & $1(11.1)$ & 0 & $2(40)^{*}$ \\
\hline $\mathrm{PPH}$ & $25(10.04)$ & $2(6.6)$ & $1(11.1)$ & 0 & 0 \\
\hline \multicolumn{6}{|l|}{ Mode of Delivery } \\
\hline Preeclampsia & $29(11.6)$ & $9(30.0)^{*}$ & $2(22.2)$ & 0 & 0 \\
\hline Abruption & $5(2.00)$ & $1(3.3)$ & $2(22.2)^{*}$ & 0 & 0 \\
\hline GDM & $3(1.20)$ & $1(3.3)$ & $1(11.1)$ & 0 & $2(40)^{*}$ \\
\hline $\mathrm{PPH}$ & $25(10.04)$ & $2(6.6)$ & $1(11.1)$ & 0 & 0 \\
\hline \multicolumn{6}{|l|}{ Fetal Outcomes } \\
\hline Preterm birth & $13(5.2)$ & $9(30)^{*}$ & $4(44.4)^{*}$ & 0 & 0 \\
\hline IUGR & $11(4.4)$ & $3(10)$ & $3(33.3)^{*}$ & 0 & 0 \\
\hline LBW & $28(11.2)$ & $9(30)^{*}$ & $6(66.6)^{*}$ & 0 & 0 \\
\hline Abortions & $6(2.0)$ & $2(6.6)$ & $2(22.2)^{*}$ & $1(14.2)$ & $1(20)$ \\
\hline Still births & $4(1.6)$ & 0 & $2(22.2)^{*}$ & 0 & 0 \\
\hline \multicolumn{6}{|l|}{ Neonatal Outcomes } \\
\hline $\begin{array}{l}\text { Respiratory distress } \\
\text { syndrome }\end{array}$ & $9(3.8)$ & $4(11.7)$ & $2(25)^{* *}$ & 0 & 0 \\
\hline Sepsis & $6(2.5)$ & $1(2.7)$ & $1(12.5)$ & 0 & 0 \\
\hline Hypoglycemia & $3(1.29)$ & $1(2.7)$ & 0 & 0 & 0 \\
\hline Hypothermia & $2(0.8)$ & $1(2.7)$ & 0 & 0 & 0 \\
\hline Intracranial bleed & $2(0.8)$ & 0 & 0 & 0 & 0 \\
\hline Necrotizing enterocolitis & $1(0.4)$ & 0 & 0 & 0 & 0 \\
\hline Early neonatal death & $4(1.7)$ & $1(2.7)$ & $1(12.5)$ & 0 & 0 \\
\hline
\end{tabular}

$* \mathrm{P} \leq 0.05$

The route of delivery in different groups were $75.5 \%$ of euthyroid, $80 \%$ of subclinical hypothyroid, $55.5 \%$ of overt hypothyroid, $71.4 \%$ of subclinical hyperthyroid, and $40 \%$ of overt hyperthyroid patients had normal vaginal delivery. The rate of cesarean section was significantly higher in patients with overt hypothyroidism (55.5 versus $15.25 \% \mathrm{P}=0.0028$ ) as compared to the euthyroid controls. No significant increase was seen in 
the subclinical hypothyroid and hyperthyroid groups. Among the various indications of cesarean section, the most common was cesarean section for fetal distress (33.3\% in overt, $6.6 \%$ in subclinical and $2.4 \%$ in overt hypothyroidism). The rate of cesarean section for fetal distress was statistically significant in overt hypothyroid patients (all other indications were equally distributed in all groups).

Fetal outcome in different groups are adverse fetal outcomes in overt hypothyroidism included spontaneous abortion $(22.2$ versus $6.6 \%, \mathrm{P}=0.045)$, preterm birth (44.4 versus $30.0 \%, \mathrm{P}=0.02)$, low birth weight $(\mathrm{LBW})$ (66.6 versus 30\%), intrauterine growth retardation (IUGR) (25 versus $4.9 \%, \mathrm{P}=0.02)$, and fetal death $(16.6$ versus $1.7 \%, \mathrm{P}=0.024$ ) as compared to the euthyroid women. All of them were found to be highly significant. Adverse fetal outcomes in subclinical hypothyroidism included spontaneous abortion (2.0 versus $6.6 \%$ ), preterm delivery (5.2 versus $30 \%)$, LBW (11.2 versus $30 \%)$, and IUGR (4.4 versus $10 \%$ ) as compared to the euthyroid women. Preterm birth was found to be statistically significant $(P=0.01)$. The mean birth weight in the euthyroid was $2.68 \pm 0.27$, in subclinical hypothyroid was $2.55 \pm 0.6$, in overt hypothyroid was $2.6 \pm 0.5$, in subclinical hyperthyroid was $2.6 \pm 0.6$, and in overt hyperthyroid was $2.5 \pm 0.10$.

Mean birth weight in overt hypothyroid was significantly lower than that in euthyroid $(\mathrm{P}=0.0001)$. Mean birth weights in subclinical hypothyroid, subclinical hyperthyroid, and overt hyperthyroid were not statistically significant. Apgar score $>7$ at 1 minute was seen in overt hypothyroid as compared to euthyroid neonates and was found to be statistically significant $(\mathrm{P}=$ 0.0080). No significant difference was found in terms of NICU admission, Apgar score $>7$ at 5 minute, and neonatal complications needing admission to NICU, except respiratory distress syndrome which was seen significantly in patients with overt hypothyroidism ( $\mathrm{P}$ $\leq 0.001$ ) in neonatal outcome. No other significant neonatal complications were seen in terms of hyperbilirubinemia, sepsis, hypoglycemia, hypothermia, intracranial bleed, necrotizing enterocolitis, and early neonatal death in different groups.

\section{DISCUSSION}

Thyroid disorders are one of the most common endocrine disorders in women during pregnancy and are associated with adverse maternal and foetal outcomes in pregnancy. However, an early detection of thyroid dysfunctions and treatment of mother during gestation improves the outcome. $^{13}$

Early detection of thyroid during pregnancy is possible if the patient is suggested thyroid function test during her first prenatal visit or soon after the pregnancy is confirmed. ${ }^{14}$ There has been a debate for a long time about the upper limit of normal TSH during pregnancy.
Recent guidelines by ATA and the National Association of Clinical Biochemists (NACB) have reduced this to 2.5 $\mathrm{m} \mathrm{IU/L}$ in $1^{\text {st }}$ trimester and $3.0 \mathrm{~m} \mathrm{IU/L}$ in $2^{\text {nd }}$ or $3^{\text {rd }}$ trimesters. This was done because it was seen that in more than $95 \%$ of rigorously screened euthyroid volunteers, the normal range was from 0.4 to $2.5 \mathrm{~m}$ IU/L. ${ }^{15}$ This of course increases the disease frequency of hypothyroidism in pregnancy up-to 5-fold. There is a wide variation in the prevalence of hypothyroidism in pregnancy $2.5 \%$ in the West to $11 \%$ in India. ${ }^{16}$

It is more in Asian countries as compared to the West. ${ }^{17}$ There are few published Indian studies on this topic. Sahu et al have done thyroid function in second trimester and reported prevalence of thyroid disorders, especially overt and subclinical hypothyroidism to be $6.47 \% .{ }^{17}$ Dhanwal et al from Delhi in 2013 reported a hypothyroidism prevalence of $14.3 \%$, with a cut off of $4.5 \mathrm{~m}$ IU/L as upper limit of normal in a cohort of 1000 pregnant women. ${ }^{18}$

Present study has shown a prevalence of $26 \%$ at a cut off of $3.0 \mathrm{~m} \mathrm{IU/L}$ as per ATA Guidelines. Various reasons have been proposed for increased prevalence of hypothyroidism in pregnancy in Asia. Increased iodine intake in diet, presence of goitrogens in diet as reported from studies in India, deficiency of micronutrients like selenium and iron are some of the reasons ascribed to high hypothyroidism prevalence in India. ${ }^{19-21}$

An inter-relation of this high prevalence of thyroid disorders with a high prevalence of the other major endocrinopathy diabetes mellitus has to be explored further. Prevalence of hyperthyroidism, both overt and subclinical in various studies has been reported to be around $1 \%$. In the present study by Nangia et al in 2013 in two hospitals together in Delhi, a prevalence of 1-2\% was found amongst 400 pregnant women. ${ }^{22}$ Further, significant adverse effects on maternal and fetal outcome were seen emphasizing the importance of routine antenatal thyroid screening. Although hyperthyroidism in pregnancy is uncommon, effects on both the mother and child are critical. However, in this study, no significant finding was seen as the sample size was small and the disease is comparatively infrequent.

There were two main drawbacks in present study: first that TPO antibody levels were not examined in all the patients and second that neonatal cord blood TSH levels were not examined in patients.

\section{CONCLUSION}

The strong point of this study is that we included a large number of subjects in this study from India. This study concludes that there is a high prevalence of hypothyroidism $(13.0 \%)$, the majority being subclinical in pregnant women, and universal screening of thyroid dysfunction may be desirable in Central-Indian Indore pregnant women. 


\section{ACKNOWLEDGMENTS}

Authors would like to sincerely appreciate the management and all staff in Department of Obstetrics and Gynaecology, Sri Aurobindo Medical College and PG Institute, Indore where this study was conducted.

Funding: No funding sources

Conflict of interest: None declared

Ethical approval: The study was approved by the Institutional Ethics Committee

\section{REFERENCES}

1. Tehrani RF, Aghaee M, Asefzadeh S. The comparison of thyroid function tests in cord blood following cesarean section or vaginal delivery. Int J Endocrinol Metab 2003;1:22-6.

2. Zadeh-Vakili A, Tehrani RF, Hashemi S, Amouzegar A, Azizi F. Relationship between sex hormone binding globulin, thyroid stimulating hormone, prolactin and serum androgens with metabolic syndrome parameters in Iranian women of reproductive age. Diabetes Metabol. 2012:1-5.

3. Stagnaro-Green A, Abalovich M, Alexander E, Azizi F, Mestman J, Negro R, et al. Guidelines of the American Thyroid Association for the diagnosis and management of thyroid disease during pregnancy and postpartum. Thyroid. 2011;21(10):1081-125.

4. Yamamoto $\mathrm{T}$, Amino $\mathrm{N}$, Tanizawa O, Doi $\mathrm{K}$, Ichihara K, Azukizawa M, et al. Longitudinal study of serum thyroid hormones, chorionic gonadotrophin and thyrotrophin during and after normal pregnancy. Clin Endocrinol (Oxf). 1979;10:459-68.

5. Glinoer D, de Nayer P, Bourdoux $P$, Lemone $M$, Robyn C, van Steirteghem A, et al. Regulation of maternal thyroid function during pregnancy. J Clin Endocrinol Metab. 1990;71:276-87.

6. Tehrani RF, Tohidi M, Rostami Dovom M, Azizi F. A population based study on the association of thyroid status with components of the metabolic syndrome. Diabete Metab. 2011;2:1-5.

7. Azizi F, Delshad H. Thyroid derangements in Pregnancy. IJEM. 2014;15:491-508.

8. Cignini P, Cafa EV, Giorlandino C, Capriglione S, Spata A, Dugo N. Thyroid physiology and common diseases in pregnancy: review of literature. J Prenat Med. 2012;6:64-71.

9. Nambiar V, Jagtap VS, Sarathi V, Lila AR, Kamalanathan S, Bandgar TR, et al. Prevalence and impact of thyroid disorders on maternal outcome in Asian-Indian pregnant women. J Thyroid Res. 2011;2011:4290-7.

10. Sahu MT, Das V, Mittal S, Agarwal A, Sahu M. Overt and subclinical thyroid dysfunction among
Indian pregnant women and its effect on maternal and fetal outcome. Arch Gynecol Obstetrics. 2010;281(2):215-20.

11. Lee RH, Miller EA, Petrove I, Braverman LE, Goodwin TM. Free T4 immunoassays are flawed during pregnancy. Am J Obstet Gynecol. 2009;200:261-6.

12. Mandel ST, Spencer CA, Hollowell JG. Are detection and treatment of thyroid insufficiency in pregnancy feasible? Thyroid. 2005;15:44-53.

13. Lazarus JH. Thyroid functions in pregnancy. Br Med Bull. 2011;97(1):137-48.

14. Banerjee S. Thyroid disorders in pregnancy. J Assoc Physicians India. 2011;59:32-4.

15. Baloch Z, Carayon P, Conte-Devolx B, Demers LM, Feldt-Rasmussen U, Henry JF et al. Laboratory Medicine Practice Guidelines. Laboratory support for the diagnosis and monitoring of thyroid disease. Thyroid. 2003;13:123-6.

16. Stagnaro-Green A. Thyroid antibodies and miscarriage: Where are we a generation later?. J Thyroid Res. 2011;2011:841-949.

17. Wang W, Teng W, Shan Z, Li J, Zhu L. The prevalence of thyroid disorders during early pregnancy in China: the benefits of universal screening in the first trimester of pregnancy. Eur J Endocrinol. 2011;164:263-8.

18. Dhanwal DK, Sudha P, Agarwal AK, Dixit V, Banerjee AK. High prevalence of subclinical hypothyroidism during first trimester of pregnancy in North India. Ind J Endocrinol Metab. 2013;17:281-4.

19. Teng X, Shan Z, Chen Y, Lai Y, Yu J, Shan L, et al. More than adequate iodine intake may increase subclinical hypothyroidism and autoimmune thyroiditis: A cross-sectional study based on two Chinese communities with different iodine intake levels. Eur J Endocrinol. 2011;164:943-50.

20. Marwaha RK, Tandon N, Gupta N, Karak AK, Verma K, Kochupillai N. Residual goitre in the postiodization phase: Iodine status, thiocyanate exposure and autoimmunity. Clin Endocrinol (Oxf). 2003;59:672-81.

21. Das S, Bhansali A, Dutta P, Aggarwal A, Bansal MP, Garg D, et al. Persistence of goiter in the postiodization phase: micronutrient deficiency or thyroid autoimmunity?. Indian J Med Res. 2011;133:103-9.

Cite this article as: Pokhanna J, Gupta U, Alwani M, Tiwari SP. Prevalence of thyroid dysfunction and impact on maternal and fetal outcome in Central Indian pregnant women. Int J Reprod Contracept Obstet Gynecol 2017;6:4666-70. 